\title{
"Lentamente a sombra da divindade ganha substância": Tradução dos poemas de Tenzin Dickie
}

Divanize Carbonieri

Resumo: O objetivo deste trabalho é discorrer sobre o processo de tradução dos poemas "Will and Testament for Aarya Tara" e "Yuthok Lane" de Tenzin Dickie, poeta oriunda do Tibete. Alguns pressupostos guiaram a tarefa: o equacionamento de aspectos fonológicos e semânticos, sem deslocamentos expressivos no campo da significância, e a tradução cultural como negociação entre valores culturais.

Palavras-chave: Tibete; significância; tradução cultural; Tenzin Dickie

\begin{abstract}
The aim of this work is to discuss the process of translating the poems "Will and Testament for Aarya Tara" and "Yuthok Lane" by Tenzin Dickie, a poet from Tibet. Some aspects that have driven this work are: the equation of phonological and semantic aspects, without significant displacements in the field of significance, and cultural translation as negotiation between cultural values.
\end{abstract}

Keywords: Tibet; significance; cultural translation; Tenzin Dickie 


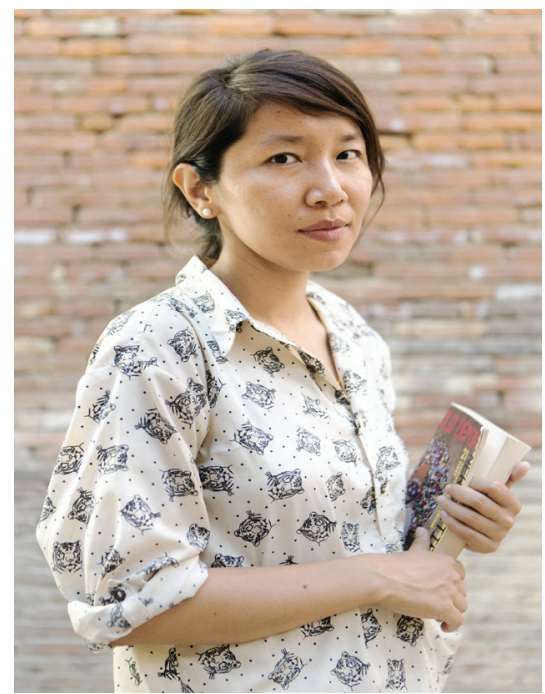

\section{Introdução}

O presente trabalho pretende discutir o processo de tradução para o português dos poemas "Will and Testament for Aarya Tara" e "Yuthok Lane" de autoria de Tenzin Dickie. O que norteou tal procedimento foi uma tentativa de equacionar os aspectos sonoros e semânticos para que se preservassem as principais imagens mobilizadas nos poemas. De acordo com Laranjeira (1993, p. 29),

não se pode separar, na prática nem na teoria da tradução poética, a forma do fundo. Muito menos ver o conteúdo como elemento traduzível e a forma - esse adorno que poetizaria o fundo - como intraduzível. Toda tradução poética supõe uma visão dialética do texto que só reconhece as oposições na medida em que se integram em uma unidade, em uma totalização essencial.

Faleiros (2015, p. 269) também alerta para a necessidade de levar em conta o "movimento dialético que se produz entre as 'equações fonológicas' e 'equações semânticas"' na tradução poética. Para ele, a maioria dos tradutores no Brasil adotou a perspectiva de Haroldo de Campos, priorizando a forma (principalmente a métrica e a rima) mesmo que isso representasse consideráveis deslocamentos 
semânticos. O resultado seria um afastamento dos leitores do complexo imagético e enunciativo do texto de partida.

Além disso, foi de fundamental relevância o conceito de tradução cultural presente em Bhabha (1990), que a entende como uma espécie de negociação de sentidos e valores entre culturas. Em seu ponto de vista, as culturas são sempre relacionadas umas às outras porque todas são embasadas por atividades simbólicas e significantes. Nesse sentido, "[a] articulação de culturas é possível não por causa da familiaridade ou similaridade de conteúdos, mas porque todas elas são práticas interpelativas formadoras de símbolos e constituidoras de sujeitos" (BHABHA, 1990, p. 209, tradução nossa).

A tradução foi, assim, vista como essa negociação entre sentidos presentes na cultura brasileira e aqueles que pareciam estar expressos nos poemas, respeitando-se as principais imagens mobilizadas.

\section{Sobre a poeta}

Tenzin Dickie é uma poeta e tradutora tibetana, com formação em Ficção e Tradução Literária pela Universidade de Columbia e Literatura Inglesa pela Universidade de Harvard. É editora de The Treasury of Lives, uma enciclopédia biográfica do Tibete, Ásia Central e região do Himalaia. Seus poemas e ensaios foram publicados nos seguintes periódicos: Indian Literature, The Yellow Nib: Modern English Poetry by Indians, Apogee Journal, Tibetan Review e Cultural Anthropology, entre outros. Em 2017, organizou e publicou a coletânea Old Demons, New Deities: 21 Short Stories from Tibet, com contos tibetanos contemporâneos de vários autores publicados pela primeira vez em inglês. 


\section{Os poemas e suas traduções}

\section{Will and Testament for Aarya Tara}

I bequeath to you

A kidney whose function is to filter regret

To the color of clear water

I bequeath to you

A heart rich enough to harvest

Despite the monsoon rains

I bequeath to you

Words that can open a secret pass

In the mountains just for you

I bequeath to you

Ears tuned to the secret prophecy

Of the oracle's return

I bequeath to you

Eyes that can catch the fall leaves falling

And cry tears of lake water

I bequeath to you

A self-determining soul forever

Awakening 


\section{Testamento para Aarya Tara}

Deixo para você

Um rim cuja função é filtrar o remorso

Até ficar claro como água

Deixo para você

Um coração rico o bastante para colher

Apesar das chuvas de monções

Deixo para você

Palavras que abrem uma passagem secreta

Nas montanhas só para você

Deixo para você

Ouvidos abertos para a profecia secreta

$\mathrm{Na}$ resposta do oráculo

Deixo para você

Olhos que veem as folhas caindo no outono

E choram um rio de lágrimas

Deixo para você

Uma alma que se autogoverna

Eternamente a despertar

Para realizar a tradução de "Will and Testament for Aarya Tara", foi necessário investigar o sentido em torno do nome Aarya Tara, que, à primeira vista, poderia ser o de uma localidade ou pessoa. De acordo com a Britannica Enciclopedia online, Tara é uma deidade budista que se apresenta de muitas formas no Tibete, Nepal e Mongólia, sendo considerada compassiva com os seres humanos: "a Tara Branca e a Tara Verde, com seus símbolos contrastantes da flor de lótus fechada ou em plena floração, simbolizam, combinadas, a compaixão infinita da divindade que trabalha dia e noite para aliviar o sofrimento". Aarya Tara é também conhecida como Tara Verde. Por tal natureza, pode ser identificada como a "Mãe Terra", entidade doadora de vida. É possível também que, no poema, esteja 
indicando alguma coletividade, a ideia de Terra num sentido político, ou seja, a nação. De qualquer forma, na tradução, optou-se por manter o nome original, uma vez que ele reverbera sentidos próprios que poderiam se perder se traduzidos.

Em inglês, existe uma diferença tradicional entre will e testament, sendo que o primeiro seria usado principalmente para as propriedades legadas (terras) e o segundo para outros tipos de bens. Essa distinção, comum em documentos medievais, por exemplo, se perdeu na atualidade, em que são tidos como sinônimos. Porém, ainda é comum o uso dos dois termos juntos numa espécie de reforço. Em português, não há essa distinção nem uso corrente. Portanto, a solução foi manter apenas "testamento".

O poema é composto por seis tercetos de versos livres (de métrica irregular), em que o primeiro verso se repete de estrofe para estrofe. Essa repetição do primeiro verso torna o poema bastante rítmico, sendo necessário mantê-la na tradução. A palavra "bequeath" dos primeiros versos oferece um tom mais formal que contrasta com a linguagem um tanto coloquial presente nos outros versos. Para manter a formalidade, poderíamos tê-la traduzido por "lego". Porém, há um paralelismo de pronúncia entre "bequeath" (bI'kwi:th) e "deixo" ("dej个u), e "deixo" participa do mesmo campo semântico de "lego". Assim, parece ter sido possível algum equilíbrio entre o aspecto semântico e o fonético.

O que a voz poética deixa ou lega para a Mãe Terra (ou para a nação) são pedaços de seu corpo: rim, coração, orelhas/ouvidos e olhos. Mas também as palavras e uma alma que se autogoverna. O sentido político de "self-determining" parece encontrar eco em "autogoverna", sendo importante mantê-lo, uma vez que a questão da independência do Tibete em relação à China é um fato crucial de sua história. Aquele que luta por uma nação independente pode morrer lutando, mas lega um sonho eternamente prestes a despertar. 


\section{Yuthok Lane}

This is how it will be:

we will take a walk on concrete, not blue tiles, and you will pretend to be disappointed.

This will have the quality of a ritual.

In the morning, the sun will fall from the sky;

we will protect ourselves against its fire.

It is not so unbearable, but we have learnt

to be wary of arrivals from the east.

We are unbeautiful here;

our stay in the plains has rendered us so.

But whispers now carry endearments,

and we will not have it any other way.

Outside the chapel,

we will collect ourselves,

then enter the bowels of this benign shell.

Nothing in here threatens us.

We will pull out our offerings, crisp and new.

This time they will go where they are intended.

The pilgrims are less urgent now. And slowly

the shadow of the deity gains its substance.

In the temple's deep, I will

speak my name for you. 


\section{Avenida Yuthok}

É assim que será:

Andaremos sobre o concreto, não sobre ladrilhos azuis,

e você fingirá se decepcionar.

Isso terá a qualidade de um ritual.

De manhã, o sol cairá do céu;

nós nos protegeremos do seu fogo.

Não é tão insuportável, mas nós aprendemos

a temer o que chega do leste.

Não somos belos aqui;

nossa estada nas planícies nos deixou assim.

Mas sussurros podem conter carinhos agora;

e não o faríamos de outra maneira.

Fora da capela, nós nos recomporemos, e adentraremos essa abençoada concha.

Nada aqui nos ameaça.

Libertaremos nossos sofrimentos, puros e novos.

Dessa vez eles irão aonde devem ir.

Os peregrinos se fazem menos ávidos. E lentamente a sombra da divindade ganha substância.

No interior do templo, eu direi

a você o meu nome.

Da mesma forma que o poema anterior, a tradução de "Yuthok Lane" encontrou certa dificuldade já a partir do título. "Lane" é uma palavra que pode ser traduzida de diversas formas em português. Yuthok Lane, em alguns lugares também chamada de Yuthok Road, é uma via no centro de Lhasa ou Lassa, a capital administrativa da Região Autônoma do Tibete na República Popular da 
China. Ao invés de "estrada" ou "rodovia", preferimos "avenida" para enfatizar a sua localização urbana e até mesmo central (o local foi palco de diversas manifestações políticas em prol da independência do Tibete).

Ainda com relação ao léxico, outra complexidade se apresentou na quarta estrofe, com as palavras "chapel” e "shell”. Provavelmente é uma referência ao Templo Jokhang, também localizado no centro de Lassa, no qual conchas aparecem como ornamentos nas paredes do pátio. No poema, o próprio templo é sentido como uma concha, uma estrutura dentro da qual se está acolhido e seguro. Talvez por isso a poeta tenha escolhido "chapel" e não "temple", já que sugere uma construção menor e mais acolhedora. De qualquer forma, a palavra "temple" aparece na última estrofe, novamente reforçando uma imagem de acolhimento: um lugar em que se pode dizer o próprio nome a outra pessoa sem correr riscos, em segurança.

Essa ideia torna inequívoco o caráter político do poema. Quando se está sendo perseguido por autoridades governamentais, proteger a verdadeira identidade pode ser uma questão de vida ou morte. Mas talvez haja também um significado espiritual, já que o nome parece carregar certo poder em várias concepções religiosas. Religiosos muitas vezes mudam de nome ou adotam diversos nomes para diferentes situações.

As estrofes do poema têm uma forma irregular, apresentando versos de variadas extensões e métricas. $\mathrm{Na}$ tradução, procurou-se manter esse aspecto. $\mathrm{O}$ entendimento foi o de que a forma ajuda a criar o efeito de subjetividades que estão desgastadas ou rotas de alguma maneira. A voz poética emprega a primeira pessoa do plural, acentuando o caráter coletivo da experiência. É um poema que fala de exílio e retorno, de desespero e alívio, de perseguição e segurança.

\section{Considerações finais}

Nas traduções propostas, manteve-se o principal conteúdo semântico dos poemas. Em alguns poucos momentos, considerou-se o aspecto sonoro como mais relevante, mas isso não resultou num considerável deslocamento de sentido. Buscou-se preservar o sentido político das composições, extremamente relevante, e, em menor grau, suas reverberações espirituais, ainda que sutis.

A tradução cultural se estabeleceu na tentativa de reconstruir um contexto para os poemas, percebido como necessário para uma compreensão mais satisfatória. Em alguns momentos, sentidos da própria cultura talvez tenham interferido na tradução ou no entendimento dos textos. Um exemplo pode ser o segredo 
em torno dos nomes de ativistas políticos, que, no Brasil, foi comum durante a ditadura militar. Talvez esse aspecto, presente no segundo poema, tenha sido lido com a contaminação do contexto da língua de chegada.

Outro exemplo talvez se refira à equiparação entre a imagem da Mãe Terra (ou Gaia) e da Tara Verde. Ainda que pareça haver convergências entre as duas figuras, certamente há especificidades marcantes. Contudo, essas contaminações ou negociações de sentidos não foram consideradas prejudiciais ao trabalho da tradução. Ao contrário, partiu-se do pressuposto de que só é possível uma compreensão parcial de outros valores culturais, se ela for mediada pela própria cultura. Não é possível abarcar todos os significados que o Outro oferece, mas é possível assumir uma postura empática, mobilizando o repertório que se conhece na sua tradução.

\section{Referências bibliográficas}

BRITANNICA ENCYCLOPEDIA. Tara: Buddhist goddess In: < https://www.britannica. com/topic/Tara-Buddhist-goddess $>$.

FALEIROS, Á. Tradução \& poesia. In: AMORIM, LM., RODRIGUES, CC., and STUPIELLO, ÉNA., orgs. Tradução e: perspectivas teóricas e práticas [online]. São Paulo: Editora UNESP; Cultura Acadêmica, 2015, pp. 263-275.

LARANJEIRA, M. Poética da tradução. São Paulo: Edusp, 1993.

BHABHA, H. apud RUTHERFORD, J. The Third Space. Interview with Homi Bhabha. In: Ders. (Hg): Identity: Community, Culture, Difference. London: Lawrence and Wishart, 1990.

Divanize Carbonieri é doutora em Letras pela Universidade de São Paulo e professora de literaturas de língua inglesa na Universidade Federal de Mato Grosso. É autora dos livros de poesia Entraves (2017), Grande depósito de bugigangas (2018), A ossatura do rinoceronte (2020) e Furagem (2020), além das coletâneas de contos Passagem estreita (2019) e Nojo (2020). Foi finalista do Prêmio Jabuti em 2020 e segunda colocada no Prêmio Off Flip em 2019, ambos na categoria Conto. Atua ainda como tradutora, tendo participado da tradução de Hind Swaraj: autogoverno da Índia de Mohandas Gandhi e 100 Grandes poemas da Índia. É editora das revistas literárias digitais Ser MulherArte e Ruído Manifesto e integra o Coletivo Maria Taquara, ligado ao Mulherio das Letras - MT. 